\title{
Tomografía computarizada cardíaca: más allá del despistaje de la enfermedad arterial coronaria
}

\author{
Cardiac computed tomography: beyond the screening of coronary artery disease
}

\author{
Pablo E. Auquilla-Clavijo ${ }^{*}$, Eduardo Pozo-Osinalde ${ }^{2}$ y Marina Povar-Echeverría ${ }^{3}$ \\ ${ }^{1}$ Servicio de Cardiología, Hospital Royo Villanova, Zaragoza; ${ }^{2}$ Unidad de imagen cardiovascular, Servicio de Cardiología, Hospital Universitario \\ Clínico San Carlos, Madrid; ${ }^{3}$ Servicio de Medicina Interna, Hospital Universitario Miguel Servet, Zaragoza. España.
}

Hoy en día la principal utilidad de la tomografía computarizada cardíaca (TCC) es el despistaje de la enfermedad arterial coronaria, no obstante, cada vez es más frecuente su empleo en el seguimiento de pacientes tras revascularización percutánea y en estudios de control de escenarios clínicos distintos, como la disección coronaria espontánea (DCE).

La DCE es una causa importante de síndrome coronario agudo (SCA) en mujeres. Según reportes, esta entidad es culpable de cerca de un cuarto de los casos de SCA en mujeres menores de 50 años ${ }^{1}$. Aunque clásicamente se creía que sobre todo afectaba a mujeres jóvenes, hoy en día está reconocido que afecta también a mujeres en edad posmenopaúsica ${ }^{2}$. En la mayoría de los casos el tratamiento suele ser conservador, pero en los pacientes que experimentan un infarto agudo de miocardio (IAM) con síntomas de isquemia recurrente o compromiso hemodinámico se puede requerir revascularización quirúrgica o percutánea ${ }^{3}$. En el caso del intervencionismo percutáneo, dada la fragilidad de la pared vascular en estos casos, el procedimiento puede tener importantes complicaciones (hematoma intramural, propagación de la disección), secundarias a la instrumentación coronaria y/o a la angioplastia. Estas complicaciones aumentan el riesgo de reestenosis o malposición tardía del stent implantado 4 . Por todo esto, en algunos casos es necesario realizar estudios de control para valorar la permeabilidad de los stents implantados y/o la evolución de la disección residual.

Presentamos el caso de una mujer de 64 años de edad y sin factores de riesgo cardiovascular, con ingreso previo tres meses antes por un IAM secundario a disección espontánea de la arteria descendente anterior (DA) con oclusión total del vaso a nivel medio, complicada con disección retrógrada periprocedimiento hacia tronco común izquierdo (TCl) y arteria circunfleja (CX). Se implantó un stent farmacoactivo en TCl-DA hasta el origen de la primera diagonal (D1), dado que la CX tenía flujo TIMI 3 se optó por tratamiento conservador sobre este vaso. En la ecocardiografía se constató función sistólica global de ventrículo izquierdo conservada, con hipocinesia de segmentos medio y apical de pared anteroseptal. La paciente fue dada de alta asintomática con tratamiento médico. Se solicitó TCC de control a las seis semanas para valorar la permeabilidad de los stents y la disección residual.

En dicho estudio se evidenció el stent largo cubriendo $\mathrm{TCl}$, DA proximal y el origen de D1, permeable y sin reestenosis, con parte de la pared haciendo impronta en la luz de la DA (Fig. 1). El stent

\section{Correspondencia:}

*Pablo Esteban Auquilla Clavijo 


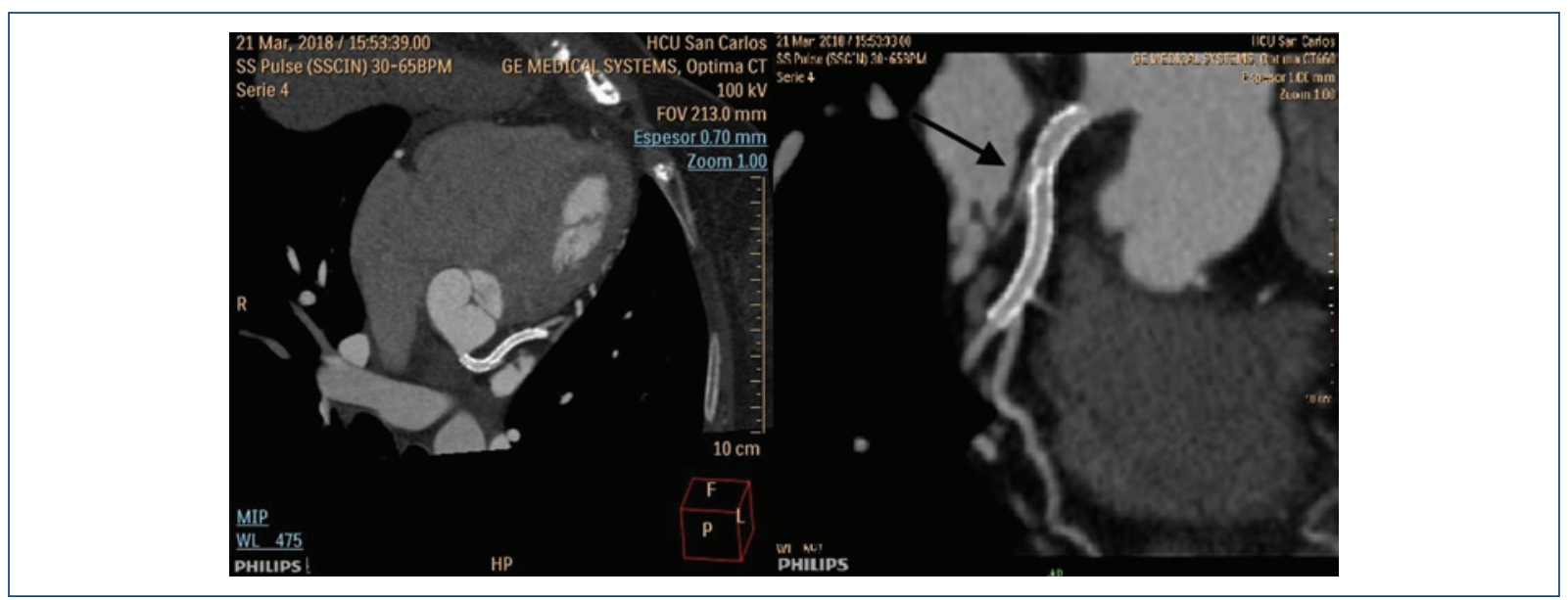

Figura 1. A la derecha de la imagen se observa en reconstrucción multiplanar la presencia de stent permeable desde el tronco común izquierdo-arteria descendente anterior hasta el origen de primera diagonal. En la imagen de la derecha se observa en reconstrucción planar curva la misma imagen; se evidencia claramente como el stent progresa hasta la primera diagonal que es un vaso de buen calibre. La flecha muestra imagen de alteración de la estructura del stent realizada para recruzar hacia la arteria circunfleja; distal a esta apertura del stent el relleno de contraste es normal.

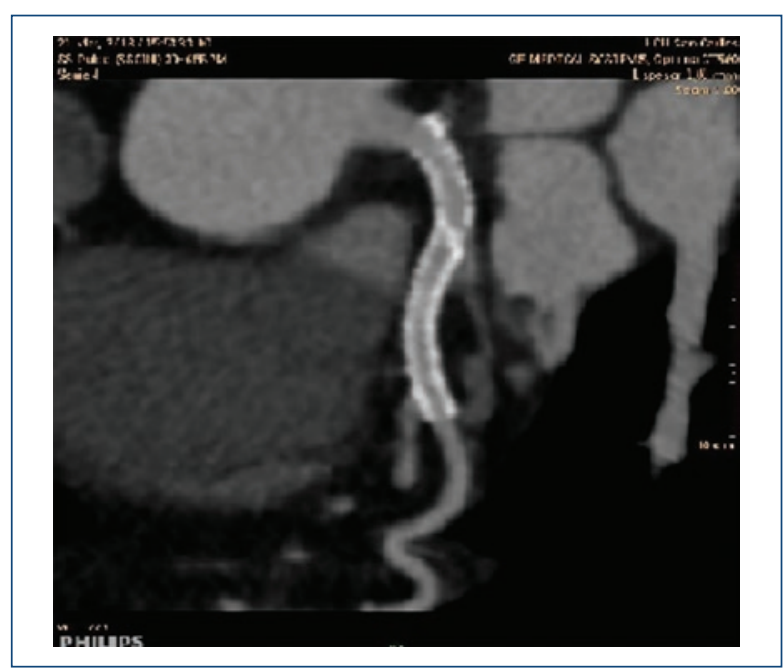

Figura 2. Se observa en reconstrucción planar curva el stent implantado en tronco común izquierdo-arteria descendente y su progresión hasta el primer ramo diagonal, con adecuado relleno distal de este.

presenta alteración de su estructura a nivel de la salida de la CX, secundaria al procedimiento realizado para recruzar hacia este vaso en la angioplastia realizada previamente (flecha); distal a esta apertura el relleno con contraste del vaso es normal (Fig. 2). La CX presenta disección residual desde su salida hasta la bifurcación con la primera marginal obtusa, con adecuado relleno de contraste en el vaso distal (Fig. 3). El estudio muestra que todos los stents implantados están permeables y la ausencia de progresión de la disección residual en la CX. La paciente ha permanecido asintomática durante todo el seguimiento.

Aunque en la mayoría de los casos la técnica diagnóstica de elección para valorar la permeabilidad de los stents es la coronariografía invasiva, existen series que muestran que en los stents implantados en el $\mathrm{TCl}$ y los segmentos proximales de los vasos epicárdicos, la TCC puede ofrecer imágenes de alta calidad para valorar la permeabilidad de los stents implantados $^{5}$. En nuestro caso se muestra la gran utilidad de la TCC como prueba no invasiva en la valoración de la integridad estructural del stent, así como la excelente definición anatómica de patologías de la pared vascular, como en este caso una disección coronaria.

\section{Conflicto de intereses}

Los autores declaran no tener ningún conflicto de intereses.

\section{Financiación}

No se recibió patrocinio de ningún tipo para realizar este artículo. 


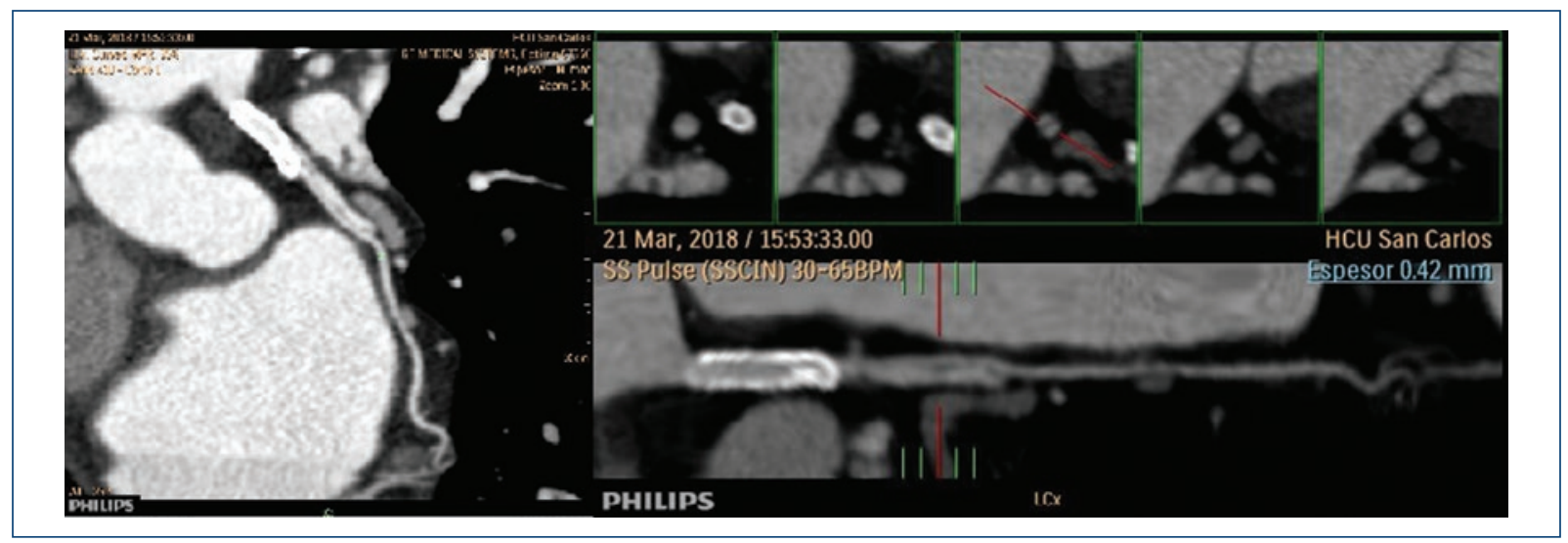

Figura 3. Se observa en reconstrucción planar curva imagen de disección de la arteria circunfleja desde su origen hasta la bifurcación con el primer ramo marginal obtuso. Se aprecia adecuado relleno de contraste en el vaso distal.

\section{Responsabilidades éticas}

Protección de personas y animales. Los autores declaran que para esta investigación no se han realizado experimentos en seres humanos ni en animales.

Confidencialidad de los datos. Los autores declaran que han seguido los protocolos de su centro de trabajo sobre la publicación de datos de pacientes.

Derecho a la privacidad y consentimiento informado. Los autores han obtenido el consentimiento informado de los pacientes y/o sujetos referidos en el artículo. Este documento obra en poder del autor de correspondencia.

\section{Bibliografía}

1. Saw J, Aymong E, Mancini GB, Sedlak T, Starovoytov A, Ricci D. Nonatherosclerotic coronary artery disease in young women. Can J Cardiol. 2014;30:814-9.

2. Saw J, Humphries K, Aymong E, Sedlak T, Prakash R, Starovoytov A, et al. Spontaneous coronary artery dissection: clinical outcomes and risk of recurrence. J Am Coll Cardiol. 2017;70:1148-58.

3. Hayes SN, Kim ESH, Saw J, Adlam D, Arslanian-Engoren C, Economy KE, et al. Spontaneous coronary artery dissection: current state of the science: A scientific statement from the American Heart Association. Circulation. 2018;137:e523-57.

4. Tweet MS, Hayes SN, Pitta SR, Simari RD, Lerman A, Lennon RJ, et al. Clinical features, management, and prognosis of spontaneous coronary artery dissection. Circulation. 2012;126(5):579-88.

5. Ehara M, Kawai M, Surmely JF, Matsubara T, Terashima M, Tsuchikane E, et al. Diagnostic accuracy of coronary in-stent restenosis using 64-slice computed tomography: comparison with invasive coronary angiography. J Am Coll Cardiol. 2007;49:951-9. 